\title{
Mobile Vaccine Vans and Drones- the Future of Vaccination Delivery System
}

\author{
Anjali Panwarr, Nandita Sharma ${ }^{2}$, Kirti Garg ${ }^{3}$, Yogesh Bahurupi ${ }^{4}$, Mahendra Singh $^{5}$, Pradeep Aggarwal ${ }^{6}$ \\ 1. MPH Scholar, Department of Community and Family Medicine, All India Institute of Medical Sciences Rishikesh; ${ }^{2} \mathrm{MPH}$ \\ Scholar, Department of Community and Family Medicine, All India Institute of Medical Sciences Rishikesh; ${ }^{3} \mathrm{MPH}$ Scholar, \\ Department of Community and Family Medicine, All India Institute of Medical Sciences Rishikesh; ${ }^{4}$ Assistant Professor, \\ Department of Community and Family Medicine, All India Institute of Medical Sciences Rishikesh; ${ }^{5}$ Assistant Professor, \\ Department of Community and Family Medicine, All India Institute of Medical Sciences Rishikesh; ${ }^{6}$ Associate Professor, \\ Department of Community and Family Medicine, All India Institute of Medical Sciences Rishikesh
}

\section{SUMMARY}

Coronavirus (SARS-CoV-2) was declared a pandemic (WHO). As a result, a significant excess in mortality threw economic systems into a tailspin. This will continue until all people worldwide are fully and effectively vaccinated. At the end of the year 2020 following the start of the vaccine, which was fraught with difficulties, there were various challenges that took a long time to resolve. Innovations in vaccination delivery systems such as mobile vaccination and its distribution using drones can be the most significant achievements in the world in terms of reaching the largest number of people possible.

\section{INTRODUCTION}

In December 2019, the first COVID-19 outbreak was reported in Wuhan, China ${ }^{[1]}$, due to severe acute respiratory syndrome coronavirus 2 (SARS-CoV-2), which quickly spread worldwide and was declared a pandemic (WHO). As a result of the COVID-19 pandemic, a significant excess in mortality threw economic systems into a tailspin ${ }^{[2]}$. This will continue until all people worldwide are fully and effectively vaccinated. On January 30 , the first verified case of COVID19 in India was discovered in Kerala, [3] and several travel-related incidents were confirmed around the country in the weeks that followed. In a span of months, remarkable efforts have been made to develop viable COVID-19 vaccines, with numerous parties working to make it happen ${ }^{[4]}$. After living the whole year with this deadly virus globally, at the end of the year 2020, on November 9, the preliminary efficacy findings for Pfizer/COVID-19 BioNTech's vaccine were published on November 18, Moderna announced 95 percent efficacy on November 16, and the Oxford and AstraZeneca group reported a wide spectrum of safety and immunogenicity of groups two days later ${ }^{[5]}$. COVID-19 vaccination began in India on January 16, 2021, with health care workers and frontline workers among the first to be vaccinated ${ }^{[6]}$. However, for vaccination, three things were very important to be carried out, such as vaccine supplies, manpower to implement them, and the people to be vaccinated $^{[7]}$.

Following the start of the vaccine, which was fraught with difficulties, there were various challenges that took a long time to resolve. Major issues related to vaccination delivery and vaccination shortage People need to go to the vaccination centers that have been designated in their specific areas, and they wait for a long time for their appointments, which poses a major threat to the program's viability. The waiting space for individuals before and after vaccinations is insufficient, and this can be one of the most dangerous regions for people to be exposed to. Healthcare workers are powerless to address this issue because they are only permitted to vaccinate a limited number of people per day and can only work at designated vaccination centers. Different innovations to the vaccination delivery system are required to lessen the strain on health care personnel as well as the obstacles that people face at vaccination centers.

CORRESPONDING AUTHOR: Pradeep Aggarwal, Associate Professor, Department of Community and Family Medicine, All India Institute of Medical Sciences Rishikesh

E Mail ID: drpradeep_aggarwal@hotmail.com

ARTICLE CYCLE: Received: 19/06/2021; Revised: 23/06/2021; Accepted: 23/06/2021; Published:30/06/2021

CITATION: Panwar A, Sharma N, Garg K, Bahurupi Y, Singh M, Aggarwal P. Mobile Vaccine Vans and Drones- the Future of Vaccination Delivery System. J Comp Health. 2021;9(1):41-43. 
Innovations such as mobile vaccination and its distribution using drones can be the most significant achievements in the world in terms of reaching the largest number of people possible. Mobile vaccination is a catch-all term for initiatives that attempt to reach a large number of people in a short period of time while using minimal resources. These initiatives have already started in several regions of the world to reach out to underserved, vulnerable, critical employees, and rural people. Public health departments, local non-governmental organizations (NGOs), health care providers, pharmacies, community organizations, and private-sector vaccinators must work together to support and coordinate mobile vaccination sites $^{[8]}$.

Jivika Healthcare Private Limited, in conjunction with IIT Hyderabad and the Bill and Melinda Gates Foundation, launched Vaccine on Wheels- India's First Doctor-based Mobile Vaccination Clinic in 2019, with the goal of ensuring access to quality vaccination for all"[9]. This type of innovation can also be done for the COVID-19 vaccination, as this is the need of the hour to disseminate COVID-19 vaccine to maximum people within a short span of time, and various states across India have initiated the use of mobile vaccine delivery systems. In March 2021, the district in Kochi launched mobile vaccination units to administer the COVID-19 vaccine to adults over 60 , serving residents of 146 old-age homes ${ }^{[10]}$. This reduces the significant burden from government bodies. Similar initiatives are also seen in Coimbatore and Gurugram. "Vaccination on Wheels," an initiative of the NGO Sakina Foundation, introduced 50 mobile vaccination vans for the needy, elder, homeless persons, and roadside hawkers in all zones of Hyderabad and other Telangana districts a few weeks ago ${ }^{[11]}$, which is helping a large number of vulnerable populations to get vaccinated. Therefore, this should be considered a major advancement of this vaccination delivery system.

In addition, Drones also played an important role in assisting in various ways, initially used exclusively for military purposes. It has also maintained public safety since the inception of the outbreak. In Dubai, they deliver stay-at-home calls and clean streets in Ahmedabad, India, and provide contactless distribution in Wuhan, China. The main issue is getting the vaccines to places where there is no transportation, and it takes many hours to walk there. There is a growing demand for the use of drones to distribute drugs to places where walking or vehicle delivery is not feasible.

Southeast Asia was among the first regions to implement drones, particularly for COVID-19 cold chain delivery, and has achieved great success in effective and efficient transportation of vaccines [12]. Drones have been used to transport samples, blood, vaccines, medications, organs, and life-saving medical equipment in a number of pilot studies ${ }^{[13]}$, so if it can be employed in any way to administer the COVID-19 vaccine, it may be able to eliminate some of the burdens.

Recently, drones have received a lot of attention from governments, organizations, and authorities as the market for contactless delivery has grown, and drones with loudspeakers have been used to communicate lockdown steps to people ${ }^{[14]}$, whereas other countries, such as China and the United States, have used drones for aerial disinfection, medical sample transportation, and consumer drone delivery [15]. It can also be used as a backup transportation system that plays a critical role in responding to the COVID-19 pandemic. It was discovered that in several scenarios, drones provide a contactfree, flexible, and fast alternative to traditional transportation modes. In addition, shows the time and cost efficiency from an academic standpoint, as no previous research has been conducted in this area ${ }^{[16]}$.

\section{Way Forward}

Therefore, we propose the following to address the pressing needs of these advances in the COVID-19 vaccine administration system. The government should provide proper guidelines for various organizations to start using these innovations i.e., mobile vaccine vans and drones, wherever possible, so that the maximum population may be reached in a short span of time while also maintaining the economy. Now is the chance to demonstrate how technological inventiveness may be extremely beneficial during the difficult times of the COVID-19 spike.

\section{REFERENCES}

1. Li Q, Guan X, Wu P, Wang X, Zhou L, Tong Y, et al. Early Transmission Dynamics in Wuhan, China, of Novel Coronavirus-Infected Pneumonia. N Engl J Med [Internet]. 2020 Jan 29 [cited 2021 May 28]; Available from:

https://www.nejm.org/doi/10.1056/NEJMoa2001316

2. World Economic Outlook Update, June 2020: A Crisis Like No Other, An Uncertain Recovery [Internet]. [cited 
2021 May 28]. Available from: https://www.imf.org/en/Publications/WEO/Issues/2020 /06/24/WEOUpdateJune2020

3. Perappadan BS. India's first coronavirus infection confirmed in Kerala. The Hindu [Internet]. 2020 Jan 30 [cited 2021 May 28]; Available from: https://www.thehindu.com/news/national/indias-firstcoronavirus-infection-confirmed-inkerala/article30691004.ece

4. Graham BS. Rapid COVID-19 vaccine development. Science. 2020 May 29;368(6494):945-6.

5. Ramasamy MN, Minassian AM, Ewer KJ, Flaxman AL, Folegatti PM, Owens DR, et al. Safety and immunogenicity of ChAdOx1 nCoV-19 vaccine administered in a prime-boost regimen in young and old adults (COV002): a single-blind, randomised, controlled, phase $2 / 3$ trial. The Lancet. 2020 Dec 19;396(10267):1979-93.

6. Perappadan BS. Coronavirus | First phase of vaccination to start on January 16 . The Hindu [Internet]. 2021 Jan 9 [cited 2021 May 28]; Available from: https://www.thehindu.com/news/national/indiato-start-covid-19-vaccination-drive-on-jan16/article33536670.ece

7. The challenges of distributing COVID-19 vaccinations - EClinicalMedicine [Internet]. [cited 2021 May 27]. Available from: https://www.thelancet.com/journals/eclinm/article/PIIS 2589-5370(20)30418-1/fulltext

8. Mobile Vaccination Resources | CDC [Internet]. 2021 [cited 2021 May 27]. Available from: https://www.cdc.gov/vaccines/covid19/planning/mobile.html

9. India's 1st Doctor based Mobile Vaccination Clinic by VOW [Internet]. Vaccine On Wheels. [cited 2021 May 28]. Available from: https://www.vaccineonwheels.com/
10. Mobile vaccination facility launched | Kochi News Times of India [Internet]. [cited 2021 May 28]. Available from:

https://timesofindia.indiatimes.com/city/kochi/mobilevaccination-facilitylaunched/articleshow/81576193.cms

11. Farooqui MM. Hyderabad: Citizens to get free ride for vaccination [Internet]. 2021 [cited 2021 May 28]. Available from: https://www.thehansindia.com/news/cities/hyderabad/ hyderabad-citizens-to-get-free-ride-for-vaccination687821

12. Adwibowo A. Assessments of heavy lift UAV quadcopter drone to support COVID 19 vaccine cold chain delivery for indigenous people in remote areas in South East Asia. medRxiv. 2021 Jan 12;2021.01.09.21249494.

13. Poljak $M$, Šterbenc $A$. Use of drones in clinical microbiology and infectious diseases: current status, challenges and barriers. Clin Microbiol Infect. 2019 Sep 1;26.

14. Spain's police are flying drones with speakers around public places to warn citizens on coronavirus lockdown to get inside [Internet]. Business Insider. [cited 2021 Jun 17]. Available from: https://www.businessinsider.in/tech/news/spainspolice-are-flying-drones-with-speakers-around-publicplaces-to-warn-citizens-on-coronavirus-lockdown-toget-inside/articleshow/74656745.cms

15. 3 ways China is using drones to fight coronavirus [Internet]. World Economic Forum. [cited 2021 Jun 17]. Available from: https://www.weforum.org/agenda/2020/03/threeways-china-is-using-drones-to-fight-coronavirus/

16. Kunovjanek $M$, Wankmüller $C$. Containing the COVID19 pandemic with drones - Feasibility of a drone enabled back-up transport system. Transp Policy. 2021 Jun 1;106:141-52. 